\title{
A Randomized Study of
} Mindfulness and Service-Learning with Students in Vietnam

Thao N. Le

University of Hawai'i at Mānoa

Nguyen Thi Kinh

Center for Humanitarian Education

Keo Douang

Phenix Association Devoir de l'Homme

\section{Recommended Citation:}




\title{
A Randomized Study of Mindfulness and Service-Learning with Students in Vietnam
}

\author{
Thao N. Le \\ University of Hawai'i at Mānoa \\ Nguyen Thi Kinh \\ Center for Humanitarian Education \\ Keo Douang \\ Phenix Association Devoir de l'Homme
}

\begin{abstract}
The study discussed in this article drew upon the service-learning and mindfulness literature to examine the effectiveness of a combined mindfulness and service-learning training in fostering awareness and civic engagement. One hundred and eighty-six university students in central Vietnam were randomized into three training groups: those receiving mindfulness only, those receiving service-learning only, and those receiving both mindfulness and service-learning. Quantitative and qualitative data were collected at baseline and at three and six months post-training. The findings reveal support for an engaged mindfulness approach to increase both mindfulness and action in improving social and community well-being. Highlighted themes include improved relationships and connections.
\end{abstract}

Keywords: education, mindfulness, service-learning, Vietnam

Loy (2015) argued that social justice, with roots in the West, and the practice of mindfulness, with roots in the East, need each other. Yet, the current burgeoning interest in secular mindfulness in the West and the exponential proliferation of mindfulness research seem to reflect minimal evidence of this integration. There is, however, a growing sentiment that the mindfulness field needs to consider and attend to issues of culture, context, class, minorities, indigenous communities, and social justice (Hick \& Furlotte, 2009; Hsu, 2016; Lavelle, 2016; Le, 2018; Magee, 2015; Proulx et al., 2018). To date, few attempts have been made to examine empirically the integration of mindfulness and service-learning, whereby mindfulness trainings are coupled with a service orientation to address a need or provide a service in the community. Further, the inclusion of groups other than Western, educated, industrialized, rich, and democratic (WEIRD) countries (Henrich, Heine, \& Norenzayan, 2010) in samples remains egregiously lacking in the majority of empirical studies on mindfulness. This study drew upon the mindfulness and service-learning literature to examine the effectiveness of a combined mindfulness and service-learning training in fostering awareness and civic engagement among a sample of native Vietnamese youth.

\section{Service-Learning}

Service-learning is a pedagogical strategy that is actively student-centered, whereby students apply critical-thinking and problem-solving skills in cycles of reflection and action to develop community projects within real-world settings. The learning is guided by theory but grounded in lived experiences (Campbell, Hamerlinck, Kim-Han, Morton, \& Snow, 2007). It is an approach to learning and teaching that focuses on practical projects and group learning activities that reflect community and societal needs (Dewey, 1916; Kilpatrick, 1918). Service-learning has its roots in the work of John Dewey (1896), who promulgated ideas and theories of progressivism, pragmatism, and experiential learning. Specifically, Dewey's educational philosophy encourages a balance of the inner (personal) with the outer (social); 
knowledge is considered embodied and lived, requiring not only the intellect and rational thought, but also the senses, experiences, and contemplation. Service-learning experiences are intentionally designed to cultivate intellectual, moral, and social sensibilities, while responsibility and civic-minded growth within the context of community-based activities are also nurtured (National Service-Learning Clearinghouse, as cited in Keen \& Hall, 2009; Williams \& Gilchrist, 2004). Students eventually develop projects that illustrate their ability to apply, in creative ways, specific knowledge and skills.

Along these lines, Palmer and Zajonc (2010) contended that the most effective forms of learning are experiential, promoting an embodied and kinesthetically, emotionally, and intellectually integrative experience. Similarly, Bruner's (1983) constructivist theory proposes that learning is a dynamic process whereby individuals actively select, transform, and retain information that resonates with how they see and perceive the world. Ideally, students in service-learning settings are challenged to think critically in the face of uncertainty (Fatih Ayaz \& Sekerci, 2015), causing changes in attitudes and preconceived notions, and developing novel perspectives and ways of seeing.

Although few rigorous studies (utilizing randomized trials and control groups) have investigated service-learning (Fatih Ayaz \& Sekerci, 2015; Harris et al., 2015; Vogler et al., 2016), findings have generally revealed positive trends in cognitive, emotional, and civic dimensions. With respect to cognitive understanding, students discover the importance of context in developing community programs. Within real-world settings, there is not necessarily a "right answer" as articulated in textbooks or lectures; rather, learners discover that what works for one particular group, at one particular time, within a given set of resources, may not necessarily yield similar results in another circumstance (Eyler, Giles, \& Braxton, 1997). This is a significant insight; as such, problem-solving and critical-thinking skills are particularly targeted (Taylor \& Trepanier-Street, 2007). Studies have also revealed increases in cooperation, collaboration, leadership skills, and attitudinal interests in helping and volunteering in the community, and engagement in the world (Allison et al., 2015; Bell, 2010; Dole, Bloom, \& Doss, 2017; Hyde \& LaPrad, 2015). Perhaps most comprehensive to date is Fatih Ayaz and Sekerci's (2015) meta-analysis of the effects of the constructivist learning approach as it relates to student academic achievement. Of the 53 studies reviewed between 2003 and 2014, 50 showed positive effects of the constructivist learning approach on student academic achievement (versus a more traditional teaching approach with no opportunity for "active" learning).

There is also a growing body of literature that has identified mindfulness as a component of or complement to a service-learning approach (Davenport \& Pagnini, 2016; Hyde \& LaPrad, 2015; LaPrad \& Hyde, 2017; Latta, Schnellert, Ondrik, \& Sasges, 2016); however, the majority of this literature remains theoretical or conceptual rather than empirical. Hyde and LaPrad (2015), for instance, noted that service and project-based learning is a mindful practice since it is both personalized learning and "democratic in its process and public exhibition" (p. 10). They made a case for mindfully democratic schools, proposing to examine social engagement as one possible outcome of this approach. They called for mindfulness (i.e., cultivation of present-moment awareness) and social justice to further connect, identifying not only the potential of mindfulness to increase one's self-regulation and support the maintenance of an ethical position to have compassion for self and others, but also the potential of mindfulness to better prepare students to engage in critical democratic citizenship (Hyde \& LaPrad, 2015).

\section{Mindfulness-Based Learning}

Loy (2015) asserted that the common ethos of the modern Western paradigm, as reflected in the socialjustice movement, comprises an external orientation of changing the world, of rectifying social, economic, and political structural malaise that causes suffering. Transforming one's unskillful habit patterns is not the primary impetus for engagement. By contrast, within the traditional Asian context, the focus has been more on transforming and refining oneself in order to co-exist harmoniously and peacefully with others, nature, society, and the cosmos, as reflected, for example, in the principles of Daoism, Confucianism, and Buddhism. For instance, the soteriological goal of traditional Asian Buddhist 
practice is liberation from suffering; this requires one to follow the Noble Eightfold Path, which includes dedicated effort around mental discipline and ethical conduct (Gunaratana, 2002). Mindfulness is the seventh path of the Noble Eightfold Path within the mental discipline group (Gunaratana, 2002) and is the component that has received the widest attention, both within popular culture and the research community.

In contemporary Western secular terminology, mindfulness has often been defined as presentmoment awareness with acceptance, without the habitual mind chatter (Kabat-Zinn, 1994). Gunaratana (2002) also defined mindfulness as "a fleeting instant of pure awareness just before you conceptualize the thing, before you identify it" (p. 132), similar to what Le Guin (1985) suggested in her essay "She Unnames Them"- the understanding that exists before the naming that limits direct perception. Within contemporary Western settings, mindfulness has been presented more as a way to attend to immanent concerns so as to live fully in the present moment rather than as a path toward freedom from suffering (e.g., nibbana). In fact, Venerable Bhikkhu Bodhi (2016) argued that alleviating "existential unease," a nagging sense of lack and dissatisfaction, is the main impetus among WEIRD individuals (Henrich et al., 2010 ) to pursue and engage in mindfulness practices.

Grossman's critique of how mindfulness has been operationalized and measured among researchers (Grossman \& Van Dam, 2011) frames mindfulness as an embodied ethical act, process, and practice (Grossman, 2015). In practicing mindfulness, one cultivates an awareness that is "conditioned by equanimity" (p. 18) with an attitude of openness, acceptance, and non- judgment, versus the common habitual pattern of avoidance or aversion to phenomena (i.e., thoughts, feelings, sensations) that are unappealing, or grasping at and clinging to thoughts and things that are appealing. Ideally, the practitioner cultivates the ability to see things as they really are, the direct perception of the true nature of all phenomena, including the nature of change and impermanence, the nature of non-self (i.e., the nonexistence of a fixed, permanent, singular self but "self" as a phenomenon and process of co-existence and relationships), as well as an understanding of the nature of suffering and liberation. Within the traditional framework, believing in a reified self is the root of greatest suffering, such that a revolution of the self is to understand and experience an embodied interdependence. Vietnamese Zen master Thich Nhat Hanh explained that to be in touch with reality and with others is to recognize that there is an interdependency, as indicated in the Majjima Nikaya (Buddhist scripture): "This is, because that is. This is not, because that is not. This is like this because that is like that.... Let us look at wealth and poverty.... The wealth of one society is made of the poverty of the other" (Nhat Hanh, 1998, pp. 32-34). In other words, individuals are responsible for each other, and the suffering of others is no different than the suffering of the self as they are interdependent.

Within the context of the Vietnam War, Thich Nhat Hanh and his spiritual community engaged in a form of nonviolent activism to help the disadvantaged and impoverished, as well as those suffering from the war (e.g., providing medical and food aid, rebuilding villages, etc.). Inspired by Mahatma Gandhi and the Reverend Martin Luther King, Jr., he coined the term engaged Buddhism as the integration of meditation and mindfulness practice with direct concrete action to reduce suffering, which aligns more with Loy's (2015) suggestion. Within a more secular framework, engaged mindfulness involves applying insights arising from mindfulness practices to alleviate economic, environmental, and societal suffering and inequities. This approach would begin to address some of the current critiques of the mindfulness movement as being too individualistic and consumerist in orientation, reflecting the entrepreneurial, neoliberal self (Hyde \& LaPrad, 2015; Loy, 2015; Payne, 2016; Walsh, 2016; Wilson, 2016). One way to encourage an engaged mindfulness approach is to incorporate both mindfulness and service-learning.

\section{Vietnam Context}

Because attention and sensitivity to context are critical components of service-learning, it is important here to briefly discuss the setting where the study of an integrated mindfulness and service-learning study was conducted - at a public university in Central Vietnam. Vietnam is currently considered a low- to middle-income country, with about $25 \%$ of its population of 96.5 million under the age of 16 
(Countrymeters, 2019). As a planned socialist-market economy, Vietnam has experienced tremendous economic growth since the mid-1980s: PricewaterhouseCoopers (2017) forecasts that with its current $5.1 \%$ GDP growth rate, Vietnam's economy may become the 20th-largest in the world. For the most part, the government has focused primarily on developing infrastructure to support economic development and much less on health, education, and social services. Some of the stress and strain associated with this strategy has arguably resulted in social, emotional, and mental health problems (e.g., Weiss et al., 2014) as well as environmental degradation (Export.gov, 2017; Nakagami, 1999). Additionally, it should be noted that as a one-party Communist state, religious practices in Vietnam are allowed but tightly restricted and controlled.

Philosophically and religiously, Buddhism has had a great influence in Vietnam. Starting with the Ly Dynasty during the 11th century, Buddhism started to flourish among the populace, as evidenced in the literature, proverbs, language, rites, and customs. The two most common forms of Buddhism were Thien (Chan, Zen) and Pure Land Mahayana sects (Nguyen, 1959). Buddhism also merged with Vietnam's folk religion of natural spirits and ancestral worship, and Confucianism, which became particularly popular from the 15th through the 19th centuries. Both philosophies flourished to varying degrees as Confucians also practiced Buddhism (Jamieson, 1993; Taylor, 1983), and the two became "intertwined, simplified, and Vietnamized" so as to constitute a "single system" that was "shared to some extent by all Vietnamese" (Jamieson, 1993, pp. 9-11). Nguyen (1959) argued that this Vietnamization of the Buddhism-Confucianism blend provided a new form of thought and energy that enabled the Vietnamese to curtail China's domination, to establish independence, and to herald independent dynasties. Emperor Tran Thai Tong of the Tran Dynasty, considered a national hero because of his victories against the Mongol armies and later China of the Sung Dynasty, explicated his philosophy in Lessons about the Sunyata, his only surviving written work (Nguyen, 1959). Advocating a harmonizing of transcendental knowledge (via Buddhism) with responsible order, relationships, and actions (via Confucianism), he suggested that the "principles of Buddhism need the wisdom of Confucianism for their penetration into human societies" (Thai Tong, as cited in Nguyen, 1959, p. 131).

We briefly offer this Vietnamese context to highlight that mindfulness (within the Buddhist framework) is not necessarily new for the Vietnamese, and that the service-learning approach of this study, discussed herein shortly, aligns with Confucian ideals of benevolence, responsibility, and respect toward others, community, and nature. Indeed, the approach of engaged mindfulness, in this iteration, could arguably be considered a small reflection of Emperor Thai Tong's vision of a Vietnamese humanism (Nguyen, 1959).

\section{Current Study}

Although the research and academic literature on the effects of mindfulness at the individual level (e.g., improving attention, decreasing anxiety, etc.) is extensive, the literature is scant at the relational level (e.g., cooperation, communication, etc.) and virtually absent at the societal level (e.g., social engagement/social justice, etc.). Personal and social transformation need one another; personal transformation alone can be self-absorbing and self-referencing, and social transformation without personal transformation can be unsustainable and untenable (Loy, 2015). The hypothesis is that an integrated mindfulness and service-learning training (engaged mindfulness) will facilitate both mindfulness and interest in serving one's community (i.e., civic engagement) as compared to mindfulness training or service-learning training only. Additionally, at least $90 \%$ of current studies on mindfulness and service-learning are conducted in Western, affluent, and developed countries, and even within these countries, inclusion of disadvantaged and resource-poor populations/communities are more the exception than the norm. As such, this study sought to address the lack of diversity in service-learning and mindfulness studies by including individuals from Vietnam, thereby broadening the external validity consideration and evidence of mindfulness and service-learning projects. 


\section{Methodology}

\section{Intervention Trainings}

Service-learning. The Duty of Man curriculum-developed by Phenix, a nongovernmental organization based in France-is a two-day (16-hour) service-learning training that is culturally tailored to reflect Vietnamese philosophical roots and the traditions of Confucianism and the Chinese Five Element theory. The training centers on the framework of the Nastrabox, whereby each of the five elements (water, fire, earth, wood, and metal) reflect a principled tool for developing a project that should be harmonious and sustainable for oneself, others, and the environment (a win-win-win strategy). For instance, the fire tool refers to understanding the conditions required from "know-how" to "can do" to "love to do" just as a fire needs oxygen, fuel, and spark to ignite. The wood tool concerns analyzing risks and opportunities, strengths, and weaknesses, just as trees in the wood thrive and grow under maximized conditions. The metal tool concerns the principle and soft skills of being sharp but flexible, just as a knife is sharp but flexible enough to follow the contours of the bones.

In this study, after receiving a lecture on the Nastrabox, groups of seven to 10 students worked collaboratively in teams to creatively develop concrete, potentially viable projects to address a critical social and environmental issue. At the end of the training, the projects were peer evaluated and ranked. Generally, the two-day training emphasizes experiential experiences via games, folk stories, and proverbs in order to foster and create a joyful atmosphere, peer connections, and collaboration. The training for this study was conducted by a seasoned practitioner who had more than 35 years of large-project design and management in the private sector, and who created the Nastrabox methodology as a form of servicelearning for students in Vietnam and France. The training was conducted in Vietnamese.

Mindfulness-based learning. The mindfulness-based learning, entitled Kỹ Năng Sống Tỉnh Thức (or skillful living with awareness), is presented as a full two-day training (16 hours) that provides the background and foundation of the mindfulness practice. Although presented in a secular format, the foundation and content of the training center on a Buddhist philosophical framework. For this study, training included discussion about the nature of the mind and mind wandering; the narrative versus experiential mind; stress and relaxation response; wholesome versus unwholesome mind states; and the relation between mind and body. The mindfulness practices, centering on mindful breathing and the body scan, lasted from two to 10 minutes and were interspersed and repeated throughout the two days. The trainings were conducted by two seasoned mindfulness practitioners (who had at least 10 years of mindfulness practice and had attended multiple retreats) in both English (by the Vietnamese-American practitioner) and Vietnamese (by the Vietnamese practitioner), providing an opportunity for students to also practice hearing English. The trainings were conducted in a circle, with experiential activities (mindfulness games, folk/wise stories, proverbs, games) and group discussions. Upon completion of the training, participants were asked to practice daily (for at least 20 minutes) for six months, and were informed that there would be another training at six months. As such, both the service-learning and mindfulness training incorporated an integrated, embodied experiential learning format of mind, body, and heart to encourage moral sensitivity, moral judgment, and moral motivation (action).

Mindfulness and service-learning. The engaged mindfulness training incorporated the mindfulness component on the first day and the service-learning component on the second day, led by the respective facilitators. The content for the mindfulness component was pared down, and although the content was similarly covered as in the full two-day training, there were fewer opportunities for practice and group discussion, and the lecture information was not as in-depth. Information was simplified for the servicelearning session and also had fewer opportunities for group work and group collaborative activities.

\section{Procedures and Data Collection}

Given Vietnam's political context, approval and permission for this study were required at multiple levels (local, district, provincial, state) and were granted due to the project director's extensive partnership and 
community-based engagement with the Centre for Humanitarian Education in Hue, Vietnam. The trainings were conducted outside of the usual university schedule, during the break, when students were studying and/or taking their comprehensive exams.

The study adopted a $2 \times 3$ factorial design. Data were collected at pre- (before the training) and at six months post-training for the quantitative measures. Participants were randomized into three conditions: (1) those who received the mindfulness training only, (2) those who received the service-learning training only, and (3) those who received the engaged mindfulness (mindfulness and service-learning) training. Participants provided qualitative reflections immediately after the training and at three and six months post-training. All measures and questions were translated into Vietnamese, and personal reflections were transcribed verbatim. Human subject approval was granted by the University of Hawai'i Office of Research Compliance.

The top four scored projects included two from the service-learning group and two from the engaged mindfulness group; each was allocated $\$ 500$ toward implementation for the following six months. The projects included beginning a water filtration system for a highland village, starting a collection to distribute warm clothing to under-resourced villagers, developing a community garden on campus, and planting trees at the university. The two projects of the engaged mindfulness group (tree planting and the community garden) were similar enough that they were combined into one called "green university."

\section{Sample}

Participants were 212 students from the University of Quang Tri in central Vietnam who attended the College of Environmental Technology, College of Construction Techniques, and College of Sciences and Technology. Quang Tri is one of 64 provinces in Vietnam, located in the north-central coastal region. Students were randomized (using a random number generator) into one of the three groups; however, the service-learning condition had the fewest participants due to the limitation of the room size where that training was conducted. The room size for the other two conditions was substantial and could accommodate up to 100 students. Additionally, 26 students (12\%) were lost at follow-up for various reasons (e.g., they had graduated, the date of data collection conflicted with their exam schedule, they were ill), resulting in a total sample of 186: 85 in the mindfulness group, 19 in the service-learning group, and 82 in the engaged mindfulness group. Regarding demographics, the mean age of the participants was 21 years (range $=17-33$ years), $56 \%$ identified as female, and $100 \%$ identified as being of Kinh ethnicity. Eleven percent were at Level 1 (equivalent to freshman standing), 17\% at Level 2, 23\% at Level 3, and $34 \%$ at Level 4 . There were no statistically significant differences across the three groups on the demographic factors.

\section{Measures}

Mindfulness. Mindfulness was assessed using the 10-item Child and Adolescent Mindfulness Measure (CAMM; Greco, Baer, \& Smith, 2010), which was developed to assess mindfulness and acceptance among youth. Examples of items include: "At school, I walk from class to class without noticing what I'm doing," "It's hard for me to pay attention to only one thing at a time," and "I push away thoughts that I don't like," with response options ranging from never true to always true in a Likertscale format. Higher scores indicate higher levels of mindfulness. The measure has been validated with a non-clinical sample of youth, showing support for internal consistency and convergent validity, and it seems to be a reliable and valid measure of mindfulness (Kuby, Mclean, \& Allen, 2015). In this sample, the alpha reliability was .68 .

Focus. Focus, or lack thereof, termed mind wandering, was assessed with two items: "How often, in the past week, did you think about something other than what you were doing?" and "How often, in the past week, were you focused on what you were doing?" Participants responded using the categories always/frequently, sometimes, and rarely. These two items were used previously by Epel et al. (2012) to study the association between telomere aging and mindfulness, and was shown to have adequate reliability and construct validity with respect to mind wandering, an aspect of mindfulness. 
Perceived stress. Perceived stress was assessed using a measure consisting of 10 items that asked participants to indicate the degree to which they felt stressed during the previous month, with response options ranging from 0 (never) to 4 (very often) on a 5-point Likert scale (Cohen, Kamarck, \& Mermelstein, 1983). Here are two examples of items: "How often have your felt nervous and stressed?" and "How often have you felt that you could not cope with all of the things that you had to do?" The scale has strong alpha coefficient and test-retest reliability (Cohen et al., 1983). Alpha reliability for this sample was .69.

Civic engagement attitudes and civic engagement behaviors. The Civic Engagement Scale (CES) was created to measure two aspects of civic engagement: attitudes and behaviors (Doolittle \& Faul, 2013). Item analysis of the 14 factors of the CES (eight attitude items and six behavior items constructed around a 7-point Likert scale) showed evidence of convergent and discriminant validity (Doolittle \& Faul, 2013). Two examples of attitude items are: "I feel responsible for my community" and "I am committed to serve in my community." The behavior items include statements such as "I help members of my community" and "I participate in discussions that raise issues of social responsibility." Alpha reliability for this sample was .75 for civic attitude and .80 for civic behavior.

Personal reflection questions. At the three- and six-month follow-ups, participants submitted personal reflections in response to the following questions: (1) "Have the practices/training affected your learning skills/style, and if so, how?"; and (2) "What insights, if any, have you experienced as a result of doing the practices?" Participants also responded to one item that asked how often they engaged in formal mindfulness practice(s) during the previous three months, on average; selection options ranged from not at all, 10-30 min per day, 30 min-1 hour, and greater than an hour each day.

\section{Quantitative Analysis}

The survey measures were analyzed using repeated multivariate analysis of variance (MANOVA), with Bonferroni correction applied for multiple comparisons. In analyzing the personal reflection questions, the authors adopted an epistemological position that was interpretative, undergirded by a processual, subjective ontology. All reflections (at baseline, three months post-follow-up, and six months postfollow-up) were transcribed, checked for accuracy, and imported into NVivo, a qualitative data-analysis software program. The reflection entries were read with an open and reflective stance and coded separately by the research team members (two master's-level research assistants). Interpretive judgments were assigned based on codes that were initially developed upon the first read-through of several reflections; additional codes were added as the narrative patterns of the reflection data revealed themselves. As themes emerged, research team members met to define, standardize, and agree on how to apply the coding themes to the data. Coding continued until saturation was reached; that is, when codes and themes became highly repetitive. The data were queried to isolate text coded as themes and then analyzed for patterns and meaning. Generally, this multiple-approach process to data increases reliability (consistency via saturation) and validity (use of multiple coders in the team, team members adopting a reflexive stance toward the analysis process, and documenting the process; Miles \& Huberman, 1994).

\section{Results}

\section{Quantitative}

Prior to conducting a repeated MANOVA, a series of Pearson correlations were performed among all the dependent variables in order to test the MANOVA assumption that the dependent variables would correlate with each other in meaningful ways (Meyers, Gamst, \& Guarino, 2006). As shown in Table 1, a pattern of correlations was observed among the dependent variables in the expected directions, with the highest correlation between civic engagement attitude at pre and civic engagement behavior at six months post, $r=.468, p<.05$; focus at six months post and stress at six months post was also moderately correlated, $r=-.370, p<.05$. Additionally, the covariance matrices among the groups were assumed to be 
equal for the purposes of the MANOVA, based on Box's test of equality of covariance matrices, which yielded a non-significant result $(p>.05)$.

Table 1. Correlations Among Study Measures

\begin{tabular}{|c|c|c|c|c|c|c|c|c|c|c|}
\hline & 1 & 2 & 3 & 4 & 5 & 6 & 7 & 8 & 9 & 10 \\
\hline 1. Mindfulness pre & 1 & & & & & & & & & \\
\hline 2. Mindfulness post & $.253 *$ & 1 & & & & & & & & \\
\hline 3. Focus pre & .067 & .010 & 1 & & & & & & & \\
\hline 4. Focus post & .008 & .131 & $-.126^{*}$ & 1 & & & & & & \\
\hline 5. Stress pre & $-.275^{*}$ & $-.171^{*}$ & $-.204^{*}$ & $-.161 *$ & 1 & & & & & \\
\hline 6. Stress post & $-.123 *$ & $-.331 *$ & .009 & $-.370^{*}$ & $.316^{*}$ & 1 & & & & \\
\hline 7. Civic Attitude pre & -.019 & -.087 & $.149 *$ & .027 & $-.185^{*}$ & .036 & 1 & & & \\
\hline 8. Civic Attitude post & -.008 & .040 & -.009 & $.135^{*}$ & -.095 & -.063 & .101 & 1 & & \\
\hline 9. Civic Behavior pre & -.028 & -.062 & .057 & -.067 & $-.230 *$ & .044 & $.468^{*}$ & .006 & 1 & \\
\hline $\begin{array}{l}\text { 10. Civic Behavior } \\
\text { post }\end{array}$ & .079 & .076 & -.053 & .115 & .005 & -.111 & -.004 & $.429 *$ & .110 & 1 \\
\hline
\end{tabular}

Note: ${ }^{*} p<.05$, one-tailed

A 2 × 3 factorial repeated measure MANOVA was conducted to test the hypothesis that there would be one or more differences between intervention (mindfulness, service-learning, both) and pre-post measure scores on mindfulness, focus, stress, civic engagement attitude, and civic engagement behavior. Results revealed no difference among the training groups across the five measures over time, $F(10,360)$ $=1.69, \mathrm{p}<.08$, eta $=.045$. However, univariate tests indicated group difference on mindfulness, $F$ $(2,183)=3.29, \mathrm{p}<.05$, eta $=.035$, and trending toward statistically significant for civic attitude, $F(2,183)$ $=2.53, \mathrm{p} .08, \mathrm{n}=.027$.

Prior to conducting a series of post-hoc analyses, the homogeneity of variance assumption was tested for all outcome measures. Based on a series of Levene's $F$ tests, the homogeneity of variance assumption was considered satisfied. Specifically, Levene's $F$ test suggested that the variances associated with all the outcome measures were homogenous $(p<.05)$.

A series of post-hoc analyses were performed to examine individual mean difference comparisons of the measures, pre versus post, across the three different interventions. In order to prevent alpha inflation at this level of the analysis, a Bonferroni correction for multiple comparisons was applied. Although the analyses did not reveal statistically significant findings, it is notable that there was a trend in the expected directions for all measures across all groups (a less conservative t-test comparison did show statistically significant findings; see Table 2). Specifically, the mindfulness-only group improved on mindfulness and focus, whereas the service-learning-only group improved on civic engagement, while the group that received both mindfulness and service-learning showed slight improvements on both measuresmindfulness and civic engagement. 
Table 2. Results of Descriptive Statistics for Study Measures

\begin{tabular}{|c|c|c|c|c|c|c|c|c|c|}
\hline \multirow{2}{*}{ Variable } & \multicolumn{2}{|c|}{ Baseline } & \multicolumn{2}{|c|}{ 6-Month } & \multirow{2}{*}{$t(84)$} & \multirow{2}{*}{$p$} & \multicolumn{2}{|c|}{$95 \% \mathrm{CI}$} & \multirow{2}{*}{$\begin{array}{c}\text { Cohen's } \\
d\end{array}$} \\
\hline & $\mathbf{M}$ & SD & M & SD & & & $L L$ & $\boldsymbol{U L}$ & \\
\hline \multicolumn{10}{|c|}{ Group 1: Mindfulness-Based Learning $(n=85)$} \\
\hline Mindfulness & 29.07 & 4.32 & 30.98 & 5.10 & -3.23 & .00 & -3.08 & -0.73 & -.35 \\
\hline Focus & 3.34 & .91 & 3.65 & .78 & -2.69 & .01 & -0.53 & -0.08 & -.29 \\
\hline Stress & 18.86 & 4.12 & 19.68 & 5.30 & -1.34 & .19 & -2.05 & 0.40 & -.14 \\
\hline $\begin{array}{l}\text { Civic } \\
\text { Engagement } \\
\text { Attitude }\end{array}$ & 44.95 & 5.66 & 44.80 & 6.20 & 0.18 & .86 & -1.54 & 1.85 & .02 \\
\hline $\begin{array}{l}\text { Civic } \\
\text { Engagement } \\
\text { Behavior }\end{array}$ & 29.11 & 5.66 & 29.95 & 61.19 & -1.03 & .31 & -2.49 & 0.80 & -.11 \\
\hline \multicolumn{10}{|c|}{ Group 2: Service-Based Learning $(n=19)$} \\
\hline Mindfulness & 32.68 & 4.46 & 30.79 & 5.19 & 1.56 & .13 & -0.63 & 4.42 & .36 \\
\hline Focus & 3.16 & 0.96 & 3.63 & 0.83 & -2.02 & .06 & -0.97 & 0.02 & -.46 \\
\hline Stress & 19.79 & 5.20 & 20.37 & 6.32 & -0.39 & .70 & -3.71 & 2.55 & -.09 \\
\hline $\begin{array}{l}\text { Civic } \\
\text { Engagement } \\
\text { Attitude }\end{array}$ & 42.11 & 8.93 & 46.47 & 5.30 & -1.80 & .09 & -9.46 & 0.72 & -.41 \\
\hline $\begin{array}{l}\text { Civic } \\
\text { Engagement } \\
\text { Behavior }\end{array}$ & 27.21 & 6.04 & 30.47 & 6.14 & -2.10 & .05 & -6.554 & 0.01 & -.48 \\
\hline \multicolumn{10}{|c|}{ Group 3: Mindfulness and Service-Based Learning $(n=82)$} \\
\hline Mindfulness & 29.77 & 4.76 & 31.21 & 5.11 & -2.03 & .05 & -2.85 & -0.03 & -.22 \\
\hline Focus & 3.37 & 0.99 & 3.57 & 0.75 & -1.49 & .14 & -0.49 & 0.07 & -.16 \\
\hline Stress & 18.94 & 5.13 & 18.38 & 4.64 & 0.90 & .37 & -0.68 & 1.80 & .10 \\
\hline $\begin{array}{l}\text { Civic } \\
\text { Engagement } \\
\text { Attitude }\end{array}$ & 45.67 & 6.28 & 45.54 & 6.15 & 0.15 & .88 & -1.65 & 1.92 & .02 \\
\hline $\begin{array}{l}\text { Civic } \\
\text { Engagement } \\
\text { Behavior }\end{array}$ & 27.80 & 6.03 & 30.07 & 6.09 & -2.39 & .02 & 4.16 & -0.38 & -.26 \\
\hline
\end{tabular}

Note: A Bonferroni correction applied for multiple comparisons showed no statistically significant findings.

At the three- and six-month follow-up reflections, participants in the mindfulness-only and mindfulness and service-learning group responded to one question that asked about their frequency of engaging in the 
mindfulness practice within the previous three months. Among the mindfulness-only group, $40 \%$ reported engaging 10 to 30 minutes per day, and $22 \%$ at least 30 minutes per day; this was slightly higher than the mindfulness and service-learning group at $27 \%$ and $19 \%$, respectively. At six months, there was a shift, with at least half in both groups reporting rarely or not at all.

\section{Qualitative}

Baseline. In response to the two reflection questions regarding how the training affected their learning style/skills, and any insights gained in applying the skills/practices, participants receiving the mindfulness training wrote on average 147 words (range $=34-257$ ), with the two most common categories expressed along the lines of self-improvement skills and awareness of self. Specifically, participants noted intentions to be more mature and responsible in an effort to benefit oneself and others (e.g., "I recognize that I am too hurried and not thoughtful-I will practice the skills every day to change my mind to live better and bring the happiness to everyone"), through calming down (e.g., "keep calm in every situation, to think before acting," "know to stop before speaking and doing something"), good communications (e.g., "we have an old saying - a greeting is more important than a tray of banquet food - this is an act to establish and maintain social relationships, brings everyone to be closer and friendlier"), and practicing values of kindness and contentment (e.g., "live with love," "open my heart broader," "learn to be satisfied with what we have and not be influenced by external situations," "if a person knows how to share and help each other, he will be happy," "we should absorb selectively and keep our values").

Similarly, self-awareness was expressed mainly as realizing certain unskillful mental habits (e.g., "hell can be in our minds," "mindfulness helps to keep the mind calm which prevents hot-temper," "the mind is flexible ... people can't choose what will happen to them but they can choose how to live," "be owner of your life - that is happiness," "find the right way and follow it and not be influenced by everything around us," "before attending the training, I attribute my actions to stress. But that is my selfishness and I shouldn't hurt anyone"). Interestingly, the usefulness of games and stories as methods for conveying the meaning of the lessons was a particularly salient category (e.g., "the games and profound stories help me to understand many things in life as well as the learning process," "from these stories I can get many precious lessons in my life," "can discover myself, my habits can be clearly revealed through games").

In response to the reflection questions at baseline, participants in the service-learning group wrote on average 142 words (range $=37-286$ ), with the common categories of using games to learn, project skills, group working skills, and service orientation emerging from the data. The most frequent and common category was the effectiveness of using games to convey training lessons; nearly every student mentioned the word games (e.g., "Although these games are simple, the deep implication in these games are useful and valuable lessons"; "I learned many lessons from the games"; "Through games I feel the meaning, thence I myself concluded: nothing is difficult, we only try, study, together contribute our efforts, we will succeed"; "The teacher taught me skills through games and those games helped everyone learn the practical lessons for themselves"). Regarding project skills, participants noted learning to develop a clear vision (e.g., "new perspective of applying five elements theory to create reasonable project") and organizational strategies (e.g., "how to set up a plan and plan what I will do"; "I have learned more knowledge on downstream flowing water in order to apply to the model to propose the problems with a view to estimate, calculate optimal, operate closely to take out the projects to benefit individuals and society"). Group working skills encompassed teamwork (e.g., "the learning is this from a saying - if you want to go fast, go alone, if you want to go far, go with a companion"; "through group games, I learned to connect with others and how to listen to other ideas"; "solidarity is important factor to decide all the work"; "a team spirit will generate power"); problem-solving skills (e.g., "There are many ways to solve a problem; each solution has its own strategy, must consider all conditions to select a reasonable solution"; "understanding others emotions, thoughts through their actions, and facial expressions"); and developing ideas collaboratively (e.g., "Do not impose your ideas and others' ideas, know the right time to awaken 
ourselves, and focus on listening"; "consensus of group members is a key to success or failure of the group"; "integrate with people around us, know how to listen, and bravely make suggestions"; "promote the talent and ebullience of members"; "In this life, no one is perfect, let us together to create a pair, offset the shortcomings to each other and together to promote these strengths, unity, the unity power will help us overcome all difficulties"). These themes have been commonly reflected in the service-learning literature (e.g., Allison et al., 2015; Dole et al., 2017).

Within the group that received both mindfulness and service-learning trainings (word mean $=111$; range $=27-290$ ), coding analysis revealed that acquiring self-improvement and project skills (mainly the subcategory of teamwork) were equally expressed in frequency and saliency; however, unlike the other two groups, these skills were more integrated such that participants reported on why these two skills were important. For instance, one participant noted that these skills help one to be a good person in society (e.g., "I learn many things about society, myself and my way of life. Every individual should have right characters and ways of life," and as similarly expressed by another, "become a useful person in society"). Another student expressed that "we need to work in group, relax, and [then] we will be success," while another reported that "I know how to balance my emotions, and make a plan, keep focused on my targets with more positive attitudes." Similarly, a student said, "This is a good opportunity for me to learn see my problems clearly, develop ideas on my subject, work with solidarity, and contribute to better environment ... learn what is good virtue for the environment," while another reported that the training provided a "life orientation, knowledge to distinguish right/wrong and be consistent." Perhaps one student summarized it best when he said:

Based on this training course, I recognize that to get success in my life, besides the professional knowledge, I must learn the essential knowledge to become a talented and virtuous person. I learn the way to relax my mind and to bear witness. I know how to ignore unessential thing.... At the same time, through the small games, I can train myself to work hard, to think about something, and respect people as well as respect the solidarity in team. In particular, something that I think I cannot do before, but now, based on this training course, I totally believe in myself that I can do it. I realized the self-confidence, hard work and team spirit are essential elements to the work of all of us.

These qualitative findings illustrated what participants considered to be most important and memorable. For mindfulness, statements centered on the personal skills of self-awareness/selfimprovement, whereas for service-learning, they concerned project development and collaborative effort. Interestingly, all groups considered the methodologies of storytelling and group games to be effective in conveying the training lessons.

Three- and six-month post-reflections. The follow-up period, at three and six months post-training, was important in assessing whether participants applied the lessons in their life and the manner in which they did it. In reviewing the reflections, the mean number of written words decreased dramatically across the three groups, to about 28 words (range $=5-78$ ) during both follow-ups, which is about one third of what was written at baseline. Consequently, data analysis was limited to exploring the frequency of words and phrases rather than gleaning for meaningful categories or themes. For the mindfulness-only group, the most commonly used words or phrases were being calm, patient, concentrate better, thinking positively, better listener, and respecting others. For instance, one participant said:

I have applied the skills learning from the training whenever my mind wanders, causing bad effects on my study or my daily work and leading to distraction. Wonderfully, I have been able to think positively and to concentrate on what I'm doing immediately.

The same participant expressed:

After learning the skills, I have had a lot of changes in my life. For example, I have no longer be impatient and have been able to concentrate on what I do. Whenever being depressed because of my study, I have contemplated to have relaxing mind. 
For the service-learning group, the most frequently expressed words and phrases included patient, good listener, and solidarity. Examples include: "I have been aware of my responsibility as a human being. I'll live not only for myself but also for our community" and "always being helpful and bringing all group members together to create solidarity." For the combined group, the most commonly expressed words were acceptance, awareness, patience, and respect, as illustrated in statements such as

when I'm stressful and anxious, I've tried my best to be aware of my breath and accept the harsh reality ... tried my best to contribute my own opinions, and help the other members enthusiastically, which helps me get along with the others better.

\section{Discussion}

The current study produced several notable findings. The results conditionally supported the hypothesis that a combined mindfulness and service-learning training for students increases both mindfulness skill and civic behavior as compared to mindfulness or service-learning training only. Interestingly, the stress measure was not significant in this study. Although the Bonferroni post-hoc analyses for multiple comparisons did not yield a statistically significant effect, more directed hypothesis testing (t-tests) did indicate significant findings. Applying a more stringent criterion that corrects for all comparisons, Bonferroni protects against a Type 1 error but elevates a Type 2 error (i.e., important differences are deemed non-significant). Some, namely epidemiologists, have argued that Bonferroni adjustments are actually unnecessary and result potentially in incorrect inferences, and should only be applied judiciously when there are many subsamples, when stratified analyses are needed, or when there is no a prior hypothesis (e.g., Perneger, 1998). Hence, we report on both statistical results. It is interesting to note that the quantitative results were corroborated in some regards by the participants' personal reflections and responses to the one-item question that queried practice and application at follow-up.

Notably, participants in the mindfulness training group reported engaging in mindfulness practices at higher percentages at follow-up as compared to the combined training group, indicating a minor dilution effect of engagement. This may indicate that the dosage of mindfulness training (16 hours vs. eight hours) is an important factor for continuity. Participants' reflections also revealed training-specific patterns and, in some ways, provided a form of training-validity checking. Importantly, they revealed participants' attitudes, beliefs, and preferences regarding the training that could be helpful in future translation/implementation of mindfulness and service-learning in a developing country. For instance, in the mindfulness training group, participants expressed that they learned self-improvement along the lines of self-management (e.g., calming oneself down) and self-awareness skills that, at follow-up, helped them experience harmony within themselves and with others. Among the service-learning group, projectrelated skills were emphasized, including knowing how to engage in teamwork and being a better listener, and at six months resulted in greater frequency of words such as patience and solidarity. Indeed, the significant finding of this group, improving slightly on civic behavior (and not attitude), also points to a common direction, that the training elevates intention to connect with others and community. The comments of the combined group suggest an integration of mindfulness and service-learning that emphasizes why awareness and project skills were important immediately after the training, and the significance of respect, values, and virtues as a direction for self and others six months later. The quantitative finding that this group improved on both mindfulness and civic behavior was also reflected in the unique personal narratives.

What was perhaps most telling and surprising was the finding that all groups noted the use of games and stories as being very effective methods for delivering the training. They remarked on how games and stories were very useful in illustrating the points being made, being both meaningful and cultivating a sense of ease and joy, and facilitating their connection with peers and others. The decrease in the number of written words in the personal reflections at follow-up, however, is potentially problematic and can be attributed to several factors: unfamiliarity with research requirements and hence low motivation to participate in research; and the teachers' lack of interaction with the participants post-training and therefore limited sustainability of not only content but relationships as well. Within a collectivist society 
such as Vietnam, fostering relationships and connections requires attending to conditions that maintain and sustain continuity. The trainers were considered teachers by the participants, and a relationship, albeit brief, had been fostered. Despite the relatively favorable comments at follow-up, there could have been much more richness had the "teachers" maintained a more consistent and reliable follow-up schedule (e.g., once every month). Further, the research team in Vietnam consisted of new collaborators and new learners to social research methods; they were learning along with the U.S. researchers about how to conduct research in Vietnam and to encourage participants' participation in line with the research requirements.

Nevertheless, these collective quantitative and qualitative findings reveal some important dimensions to consider in conducting mindfulness and/or service-learning in Vietnam. The first is the importance of process and context. Learning is a process that occurs within a social life, and that intervention and any resultant potential changes will surely be accommodated within each participant's biography, which includes the everyday context. Vietnam has a long-situated history and experience in Buddhism and Confucianism that influences individuals' values, beliefs, and attitudes, which are realized every day by individuals in some form or fashion. We observed that study participants readily and eagerly accepted the training and interpreted it as useful and meaningful to them.

The second point of consideration is that individuals are creatures of habit, as reflected in thought patterns, causal frameworks, and ways of interpreting the world. Much of learning can be regarded simply as the layering of new content information on prior, conditioned, habitual mental frameworks. The intent of service-learning, however, is to provide an experiential, transformative experience that can potentially disrupt, dislodge, and plant new frames of reference (ideas, beliefs, attitudes, assumptions, expectations) for interpreting the world. These new frames of reference would be those that are "more inclusive, differentiating, permeable (open to other viewpoints), critically reflective of assumptions, emotionally capable of change, and integrative of experience" (Mezirow, 2000, p. 19). Using LeGuine's metaphor of a starfish, Strain (2007) contended that service-learning is an incremental learning process whereby movement/changes can occur along several vectors and dimensions, and at different rates and times. It does not necessarily have to be a shift toward social justice, although that is a commonly stated objective of service-learning (Eyler \& Giles, 1999), but also along lines of personal and moral transformation (Strain, 2005, 2007). In the students' reflections, with commonly expressed words like patience and acceptance, there appeared to be movement toward inclusivity and an other-oriented framework. Strain (2007) also argued for distinction between empathy and charity in service-learning; in other words, programs need to move beyond a charity orientation toward a caring and critical-reflection orientation. Indeed, the reflections of the students suggest a more caring orientation, rather than a social-justice orientation, reflective of a relational ontology ("I am because you are").

The third point of consideration is the very eager uptake of stories and games, with Vietnamese students expressing that this modality helped them to learn, absorb, and apply the learning to everyday life. This was a compelling, significant, and recurrent theme across all three groups. Related to the previous point about habitual mental frameworks, Martin Shaw (as cited in DuCann, 2018), a notable storyteller, argued that storytelling (and games) has the potential to "uncolonize" the imagination because, in the process of listening to a story, one actively creates possibilities and beholds them in one's mind. Rather than showing a picture of a dog and saying, "This is a dog" (a final resolution), the process of hearing the word $d o g$ creates infinite possibilities because a dog exists in everyone's mind differently (DuCann, 2018). A proverb expressed in a game can generate different meanings and imaginings among different individuals, depending on what has happened or what is currently happening in the person's life. Shaw (as cited in DuCann, 2018) expressed that folk tales told well have the power to help listeners to be truly human. Indeed, storytelling seems to be an effective way to inspire and embed some of the principles of mindfulness and service-learning. 


\section{Limitations}

How does the newly acquired understanding (self-awareness, project skills, patience, acceptance, etc.) reported by participants in this study become embodied and enacted over time? Dewey articulated a foundation for a situated relationship of awareness, reflection, and action in everyday living, similar to the engaged mindfulness approach explored in this study; however, a six-month timeframe and survey measures are simply not sufficient to capture the complexity of possible changes. Therein lies one of the greatest limitations of this study. Such a limitation could be addressed in future studies by applying a multimodal methodology. More specifically, a longitudinal multimodal methodology would be able to capture in situ how participants engage with the materials of the learning, the cultural artifacts used (e.g., proverbs, stories), and the practices (e.g., mindfulness), and how this then transforms dynamically in terms of moral action over time. Being able to capture intensity, frequency, duration, and depth of engagement would enable a richer understanding of the embodied experience.

Another limitation of the study concerns the limited monitoring of progress, report feedback, and support for the participants, which was constrained to baseline, at three months and at six months. In this constructivist-based theoretical framework of service/project-based learning, students are regarded as active agents engaged in authentic real-life problem-solving tasks. They are applying their newly acquired knowledge and skills within a dynamic interaction with their physical and social environment. However, this constructivist approach requires a balance with structured, instructional guidance, perhaps weekly if not monthly. Key to service-learning is using oral and written reflection exercises that are structured and regular to connect cognitive inquiry with the experience of service. This level of engagement, however, was outside the purview of this study; hence, it was difficult to actually monitor students' progress, give feedback and support, clarify values, and provide additional tools when and where they were needed. In a study with 22,235 college undergraduates, Astin, Vogelgesang, Ikeda, and Yee (2000) noted that the opportunity to process the service-learning experience is crucial, with teachers connecting the experience with course material to deepen integration of the material. Arguably, a similar case can be made for the mindfulness training experience. Thus, a limitation of the study was the lack of in-depth monitoring that would be required for more embedded, enacted outcomes. Likewise, reflection assignments of action/reflection and experience/abstraction (Kolb \& Kolb, 2017) need to occur more periodically and frequently, not simply three and six months post-training. Certainly, self-integration is a labor over time, and the ability to capture these dynamic changes requires laborious data collection as well.

The third limitation concerns the issue of statistical power and unequal sample sizes. Constrained by the room size when the trainings were simultaneously being conducted, the randomization process resulted in unequal sample sizes. In addition to attrition at follow-up (12\%), this led to a lack of sufficient power to detect statistical significance, as revealed in the Bonferroni analysis. Although not statistically significant, the qualitative results suggest a practical significance in the way students reported acquiring life skills that were useful and beneficial to their lives, and differentially across the three groups.

The fourth limitation concerns random assignment. Although random assignment has the potential to reduce threats to internal validity, it can create special conditions that are difficult to replicate in other contexts.

Finally, through the use of random assignment and survey measures, the study itself partially adopted a positivistic, empirical approach, with underlying assumptions around reality and cause and effect. For instance, random assignment minimized confounding factors along with intention to control conditions. This reductionist framework has been argued to be limiting, particular with respect to Asian and Indigenous epistemology that regards meaning and truth as embedded within relations, cultural context, and multidimensionality (Ames \& Hall, 2003). In other words, there is no "objective" truth per se; rather, truth arises out of subjective interpretations embedded within space and time, and what is most important is whether the resultant knowledge leads to intentions and actions that are beneficial to self, others, and community (Ames \& Hall; Meyers, 2008). There is an acknowledgement that there is an infinite number of causes that may have resulted in the reported set of findings. This study suggests that within this specific group of students, at a particular time, and within a particular set of trainings, there were ripening 
conditions for a certain unfolding of outcomes among the participants. Hence, there is no intention to generalize or universalize the results. These findings are presented within certain constraints and conditions that are fully acknowledged; additionally, there are certainly many other factors that have not been considered or measured.

\section{Conclusion}

Most programs/trainings on mindfulness do not include an explicit ethics, virtue, or values component. By including service-learning, the intent of this study was to examine experiential training in which virtues/values were explicitly considered. The Duty of Man service-learning training is presented within an implicit Confucian framework that frames moral sensibility and action around roles and responsibilities to oneself, to family/others, and to nature/environment. Students in the study were encouraged to develop projects that reflected this framework, which is also consistent with Dewey's (1916) assertion that education must have a social component, with public interest in mind so as to foster human flourishing. Yet, if mindfulness is regarded as a beneficial practice, then it must be understood within the cultural context of participants' lives (Cannon, 2016).

One of the criticisms of the current mindfulness movement is its lack of culturally relevant pedagogy to reach diverse populations and communities. It is criticized for potentially acting as another form of Western colonization - that is, of doing good as simply importing mindfulness to marginalized communities. However, if compassion and interdependence are tied to concrete pathways to enact these principles, and service, community empowerment, and social justice are the resultant outcomes, then this could be a new paradigm in mindfulness education. Emperor Tran Thai Tong had asserted that the principles of Buddhism need the wisdom of Confucianism to penetrate human societies. This study's integration of mindfulness and a service-learning framework is perhaps one example of Emperor Thai Tong's remarkable vision being enacted.

\section{References}

Allison, P., Gray, S., Martindale, R., Nash, C., Sproule, J., \& Wang, J. (2015). Exploring contributions of project-based learning to health and wellbeing in secondary education. Improving Schools, 18(3), 207-220. https://doi.org/10.1177/1365480215599298

Ames, R., \& Hall, R. (2003). Daodejing: "Making this life significant." New York, NY: Random House.

Astin, A. W., Vogelgesang, L. J., Ikeda, E. K., \& Yee, J. A. (2000). How service-learning affects students. Los Angeles, CA: Higher Education Research Institute, UCLA. Retrieved from http://digitalcommons.unomaha.edu/slcehighered

Bell, S. (2010). Project-based learning for the 21 st century: Skills for the future. The Clearing House: $A$ Journal of Educational Strategies, Issues and Ideas, 83(2), 39-43. doi:10.1080/00098650903505415

Bodhi, B. (2016). The transformation of mindfulness. In R. E. Purser, D. Forbes, \& A. Burke (Eds.), Handbook of mindfulness: Culture, context, and social engagement (pp. 3-14). Cham, Switzerland: Springer. doi:10.1008/978-3-319-44019-4_1

Bruner, J. (1983). Child's talk: Learning to use language. Oxford, UK: Oxford University Press.

Campbell, J., Hamerlinck, J., Kim-Han, J., Morton, K., \& Snow, L. (Eds.). (2007). Civic engagement in higher education: Reflection power evaluation risk management. Boston, MA: Campus Compact.

Cannon, J. (2016). Education as the practice of freedom: A social justice proposal for mindfulness educators. In R. E. Purser, D. Forbes, \& A. Burke (Eds.), Handbook of mindfulness: Culture, context, and social engagement (pp. 397-410). Cham, Switzerland: Springer International. doi:10.1007/978-3-319-44019-4

Cohen, S., Kamarck, T., \& Mermelstein, R. (1983). A global measure of perceived stress. Journal of Health and Social Behavior, 24(4), 386-396. 
Countrymeters. (2019). Vietnam population. Retrieved from http://countrymeters.info/en/ Vietnam\#age_structure

Davenport, C., \& Pagnini, F. (2016). Mindful learning: A case study of Langerian mindfulness in schools. Frontiers in Psychology, 7. doi:10.3389/fpsyc201601372

Dewey, J. (1896). The reflex arc concept in psychology. Psychological Review, 3, 357-370.

Dewey, J. (1916). Democracy and education. New York, NY: The Macmillan Company. Retrieved from http://www.ilt.columbia/edu/publications/dewey.html

Dole, S., Bloom, L., \& Doss, K. K. (2017). Engaged learning: Impact of PBL and PjBL with elementary and middle grade students. Interdisciplinary Journal of Problem-Based Learning, 11(2).

Doolittle, A. \&. Faul, A. C. (2013). Civic engagement scale: A validation study. SAGE Open. Retrieved from http://sgo.sagepub.com/content/3/3/2158244013495542

DuCann, C. (2018). Uncolonising the imagination [Blog post]. Retrieved from http://www.dailygood.org/story/1979/uncolonising-the-imagination-charlotte-du-cann/

Epel, E. S., Puterman, E., Lin, J., Blackburn, E., Lazaro, A., \& Mendes, W. B. (2012). Wandering minds and aging cells. Clinical Psychological Science, 1(1), 75-83. Retrieved from http://cpx.sagepub.com/content/early/2012/11/06/2167702612460234

Export.gov. (2017). Vietnam-Environmental and pollution control equipment and services. Retrieved from https://www.export.gov/article?id=Vietnam-Environmental-and-Pollution-ControlEquipment-and-Services

Eyler, J., \& Giles, D., Jr. (1999). Where's the learning in service-learning? San Francisco, CA: JosseyBass.

Eyler, J., Giles, D., Jr., \& Braxton, J. (1997). The impact of service-learning on college students. Michigan Journal of Community Service Learning, 4(1), 5-15.

Fatih Ayaz, M., \& Sekerci, H. (2015). The effects of the constructivist learning approach on student's academic achievement: A meta-analysis study. TOJET: The Turkish Online Journal of Educational Technology, 14(4), 143-156.

Greco, L. A., Baer, R. A., \& Smith, G. T. (2011). Assessing mindfulness in children and adolescents: Development and validation of the child and adolescent mindfulness measure (CAMM). Psychological Assessment, 23(3), 606-614. doi: 10.1037/a0022819

Grossman, P. (2015). Mindfulness: Awareness informed by an embodied ethic. Mindfulness, 6(1), 17-22.

Grossman, P., \& Van Dam, N. T. (2011). Mindfulness by any other name...: Trials and tribulations of sati in western psychology and science. Contemporary Buddhism, 12(1), 219-239.

Gunaratana, H. (2002). Mindfulness in plain English. Boston, MA: Wisdom Publications.

Harris, C. J., Penuel, W. R., D’Angelo, C. M., DeBarger, A. H., Gallagher, L. P., Kennedy, C. A., Cheng, B. H., \& Krajcik, J. S. (2015). Impact of project-based curriculum materials on student learning in science: Results of a randomized controlled trial. Journal of Research in Science Teaching, 52(10), 1362-1385. doi:10.1002/tea.21263

Henrich, J., Heine, S. J., \& Norenzayan, A. (2010). The weirdest people in the world? Behavioral and Brain Sciences, 33(2-3), 61-83. doi:10.1017/S0140525X0999152X

Hick, S. F., \& Furlotte, C. R. (2009). Mindfulness and social justice-oriented approaches: Bridging the mind and society together in social work practice. Canadian Social Work Review, 26(1), 5-24.

Hsu, F. (2016). What is the sound of one invisible hand clapping? Neoliberalism, the invisibility of Asian and Asian American Buddhists, and secular mindfulness in education. In R. E. Purser, D. Forbes, \& A. Burke (Eds.), Handbook of mindfulness: Culture, context, and social engagement (pp. 369382). Cham, Switzerland: Springer. doi:10.1007/978-3-319-44019-4

Hyde, A. M., \& LaPrad, J. G. (2015). Mindfulness, democracy, and education. Democracy and Education, 23(2), 1-12.

Jamieson, N. L. (1993). Understanding Vietnam. Berkeley, CA: University of California Press.

Kabat-Zinn, J. (1994). Wherever you go, there you are: Mindfulness meditation in everyday life. New York, NY: Hyperion Press. 
Keen, C., \& Hall, K. (2009). Engaging with difference matters: Longitudinal student outcomes of cocurricular service-learning programs. Journal of Higher Education, 80(1), 59-79.

Kilpatrick, W. H. (1918). The project method: The use of the purposeful act in the educative process. New York, NY: Teachers College, Columbia University.

Kolb, A. Y., \& Kolb, D. A. (2017). Experiential learning theory as a guide for experiential educators in higher education. ELITHE: A Journal of Engaged Educators, 1(1), 7-44.

Kuby, A. K., McLean, N., \& Allen, K. (2015). Validation of the child and adolescent mindfulness measure (CAMM) with non-clinical adolescents. Mindfulness, 6(6), 1448-1455. doi:10.1007/s12671-015-0418-3

LaPrad, J. G., \& Hyde, A. M. (2017). IDEAS: A qualitative inquiry into project-based learning. The Qualitative Report, 22(2), 479-498. Retrieved from https://nsuworks.nova.edu/tqr/vol22/iss2/8

Latta, M. M., Schneller, L., Ondrik, K., \& Sasges, M. (2016). The inspirited nature of mindful curricular enactment's community (re)making. Journal of Curriculum Studies, 49(3), 255-272.

Lavelle, B. D. (2016). Against one method: Contemplation in context. In R. E. Purser, D. Forbes, \& A. Burke (Eds.), Handbook of mindfulness: Culture, context, and social engagement (pp. 233-242). Cham, Switzerland: Springer. doi:10.1007/978-3-319-44019-4

Le Guin, U. K. (1985, January 21). She unnames them. The New Yorker, 27.

Loy, D. (2015). A new Buddhist path: Enlightenment, evolution, and ethics in the modern world. Somerville, MA: Wisdom Publications.

Magee, R. V. (2015). The way of ColorInsight: Understanding race and law effectively through mindfulness-based ColorInsight practices. Georgetown Law Journal of Modern Critical Race Perspectives, 8, 251-304. Retrieved from https://ssrn.com/abstract=2638511.

Meyers, L. S., Gamst, G., \& Guarino, A. J. (2006). Applied multivariate research. Thousand Oaks, CA: Sage.

Meyers, R. B. (2002). A heuristic for environmental values and ethics, and a psychometric instrument to measure adult environmental ethics and willingness to protect the environment (Doctoral dissertation). Retrieved from https://etd.ohiolink.edu/!etd.send file?accession=osu1039113836\&disposition=inline.

Mezirow, J. (2000). Learning to think like an adult: Core concepts of transformation theory. In J. Mezirow \& Associates (Eds.), Learning as transformation: Critical perspectives on a theory in progress (pp. 3-33). San Francisco, CA: Jossey-Bass.

Miles, M. B., \& Huberman, A. M. (1994). Qualitative data analysis (2nd ed.). Thousand Oaks, CA: Sage.

Nakagami, K. (1999). Environmental management and sustainable development in Vietnam. Retrieved from http://www.ps.ritsumei.ac.jp/assoc/policy_science/071/

071_05_nakagami.pdf

Nguyen, D. T. (1959). Vietnamese humanism. Philosophy East and West, 9(3/4), 129-143.

Nhat Hanh, Thich. (1998). Interbeing: Fourteen guidelines for engaged Buddhism. Berkeley, CA: Parallax Press.

Palmer, P. J., \& Zajonc, A. (2010). The heart of higher education: A call to renewal. San Francisco, CA: Jossey-Bass.

Payne, R. K. (2016). Mindfulness and the moral imperative for the self to improve the self. In R. E. Purser, D. Forbes, \& A. Burke (Eds.), Handbook of mindfulness: Culture, context, and social engagement (pp. 121-134). Cham, Switzerland: Springer International. doi:10.1007/978-3-31944019-4

Perneger, T. V. (1998). What's wrong with Bonferroni adjustments. British Medical Journal, 316(7139), $1236-1238$.

PricewaterhouseCoopers. (2017). The long view: How will the global economic order change by 2050? Retrieved from https:/www.pwc.com/gx/en/world-2050/assets/pwc-the-world-in-2050-fullreport-feb-2017.pdf

Proulx, J., Croff, R., Oken, B., Aldwin, C., Fleming, C. M., Bergen-Cico, D., Le, T. N., \& Noorani, M. (2018). Considerations for research and development of culturally relevant mindfulness 
interventions in African minority communities. Mindfulness, 9(2), 361-370. doi:10.1007/s12671017-0785-z

Strain, C. R. (2005). Pedagogy and practice: Service-learning and students' moral development. New Directions for Teaching and Learning, 103, 61-72. doi:10.1002/t1.204

Strain, C. R. (2007). Moving like a starfish: Beyond a unilinear model of student transformation in service-learning classes. Journal of College and Character, 8, 1-12. doi:10.2202/1940-1639.1150

Taylor, J., \& Trepanier-Street, M. (2007). Civic education in multicultural contexts: New findings from a national study. The Social Studies, 98(1), 14-18.

Taylor, K. W. (1983). The birth of Vietnam. Berkeley, CA: University of California Press.

Vogler, J. S., Thompson, P., Davis, D. W. Mayfield, B. E., Finley, P. M, \& Yasseri, D. (2018). The hard work of soft skills: Augmenting the project-based learning experience with interdisciplinary teamwork. Instructional Science, 46(3), 457-488.

Walsh, Z. (2016). A meta-critique of mindfulness critiques: From McMindfulness to critical mindfulness. In R. E. Purser, D. Forbes, \& A. Burke (Eds.), Handbook of mindfulness: Culture, context, and social engagement (pp. 153-242). Cham, Switzerland: Springer. doi:10.1007/978-3-319-44019-4

Weiss, B., Dang, M., Trung, L., Nguyen, M. C., Thuy, N. T., \& Pollack, A. (2014). A nationallyrepresentative epidemiological and risk factor assessment of child mental health in Vietnam. International Perspectives in Psychology, 3(3), 139-153.

Williams, B. N., \& Gilchrist, L. Z.(2004). Civic learning via service-learning: A proposed framework and methodology to linking servant leadership theory to the contemporary practice of community policing. Global Virtue Ethics Review, 5(3), 80-94.

Wilson, J. (2016). Selling mindfulness: Commodity lineages and the marketing of mindful products. In R. E. Purser, D. Forbes, \& A. Burke (Eds.), Handbook of mindfulness: Culture, context, and social engagement (pp. 109-119). Cham, Switzerland: Springer. doi:10.1007/978-3-319-44019-4

\section{Acknowledgments}

We extend abundant gratitude to Kim Phuong Thi Le, Kim Thoa Boytard, Nguyen Le Nhien Huong, Jacqueline Tanni, Leysa Cerswell, Dave Alefaio, and the University of Quang Tri for assistance with data collection, translation, coding, the literature review, and editing. Funding was provided through the Mind $\&$ Life 1440 Award. Any views, findings, conclusions, or recommendations expressed in this article do not necessarily reflect those of the Mind \& Life Institute.

\section{About the Authors}

Thao N. Le is Associate Professor in the Family and Consumer Sciences Department at the University of Hawai'i at Mānoa.

Nguyen Thi Kinh is associated with the Center for Humanitarian Education.

Keo Douang is associated with the Phenix Association Devoir de l'Homme.

Correspondence concerning this article should be addressed to Thao N. Le at thaole3@hawaii.edu. 